\title{
Role of Universal Cystourethroscopy to detect Lower Urinary Tract Injuries during Gynecological Surgery
}

\author{
${ }^{1}$ Raveendra P Gondhali, ${ }^{2}$ Vineet Mishra, ${ }^{3}$ Sumesh Choudhary, ${ }^{4}$ Rohina Aggarwal, ${ }^{5}$ Priyankur Roy
}

\section{ABSTRACT}

\section{Objective:}

- To determine the incidence of urinary tract injuries during gynecological surgeries.

- To explore the role of universal cystourethroscopy to detect lower urinary tract injuries during gynecological operations to reduce postoperative morbidity and its sequelae.

Study design: A prospective observational study.

Settings: A tertiary care center.

Materials and methods: This was an observational study conducted in 163 women who underwent gynecological surgery at our department during August 2014 to May 2017.

Results: Data are classified according to demography, type, and indication of surgery performed in 163 consecutive subjects. History of previous pelvic surgery, if any, was taken into account to correlate with incidence of lower urinary tract injury intraoperatively. The ureteric and bladder injuries detected by routine intraoperative cystourethroscopy were tabulated. Intraoperatively detected rates of silent ureteric and bladder injury by cystourethroscopy are higher than obvious visually inspected injuries. We obtained intraoperatively ureteric injury rate of $0.61 \%$ and a bladder injury rate of $4.29 \%$ detected by cystourethroscopy. In two patients (1.23\%), in spite of blood-stained urine in urobag, we could not detect any lower urinary tract injury. On long-term follow-up, two subjects (1.23\%) attended outpatient department with ureterovaginal fistula and one subject $(0.61 \%)$ developed vesicovaginal fistula.

Conclusion: Use of intraoperative universal cystourethroscopy during gynecological operations should be considered routinely to detect unsuspected lower urinary tract injuries and immediate management to prevent its long-term sequelae.

Keywords: Gynecological surgery, Lower urinary tract injury, Universal cystourethroscopy.

How to cite this article: Gondhali RP, Mishra V, Choudhary S, Aggarwal R, Roy P. The Role of Universal Cystourethroscopy

\footnotetext{
${ }^{1,3}$ Assistant Professor, ${ }^{2}$ Professor and Head, ${ }^{4}$ Professor, ${ }^{5}$ Tutor

${ }^{1-4}$ Department of Obstetrics and Gynecology, Smt. G. R. Doshi \& Smt. K. M. Mehta Institute of Kidney Diseases \& Research Centre, Ahmedabad, Gujarat, India

${ }^{5}$ Department of Obstetrics and Gynecology, North Bengal Medical College \& Hospital, Siliguri, West Bengal, India

Corresponding Author: Vineet Mishra, Professor and Head Department of Obstetrics and Gynecology, Smt. G. R. Doshi \& Smt. K. M. Mehta Institute of Kidney Diseases \& Research Centre, Ahmedabad, Gujarat, India, e-mail: vineet.mishra.ikdrc@ gmail.com
}

to detect Lower Urinary Tract Injuries during Gynecological Surgery. J South Asian Feder Menopause Soc 2018;6(1):26-29.

Source of support: Nil

Conflict of interest: None

Date of received: 10 January 2018

Date of acceptance: 27 January 2018

Date of publication: August 2018

\section{INTRODUCTION}

Gynecological surgery can have various intra- and postoperative complications from minor injury to lower urinary tract to major postoperative morbidity demanding surgical correction.

Lower urinary tract injuries are more common during gynecological surgeries due to close embryological development and proximity of genitourinary system. Urological injuries are less common when vaginal route is preferred over abdominal or endoscopic, wherever possible. $^{1}$

The morbidity associated with injury and its management sequelae may result in temporary or permanent physical, psychological, or financial disability causing litigations and hampers quality of life of patient. ${ }^{2,3}$

Thus, intraoperative recognition of injury and its immediate management prevents postoperative morbidity in the patients. ${ }^{4}$ There is fivefold higher rate of detection of injuries after universal cystourethroscopy intraoperatively. ${ }^{5}$

During pelvic surgeries, incidence of ureteric injuries is 0.2 to $1.0 \%$ out of which $50 \%$ are gynecological surgeries. ${ }^{6,7}$

The risk of ureteric injuries is higher after laparoscopic hysterectomy compared with abdominal or vaginal hysterectomies. ${ }^{8}$

According to the guideline of The American College of Obstetricians and Gynecologists (ACOG), ${ }^{9}$ released in 2007, intraoperative cystoscopy should be used selectively after prolapse or urinary incontinence correction procedures. In 2012, the American Association of Gynecologic Laparoscopist $^{10}$ suggested cystourethroscopic evaluation after all total laparoscopic hysterectomy procedures. The quality indicators (NFQ 2063) published by The National Quality Forum also recommend the use of routine cystoscopy in 
selected cases only. But till date, there are no strict guidelines regarding the role of universal cystourethroscopy.

The purpose of our study was to find out the role of intraoperative universal cystourethroscopy to detect lower urinary tract injuries during gynecological surgeries. And if any injury is detected, its immediate correction is done intraoperatively to prevent long-term postoperative morbidity.

\section{MATERIALS AND METHODS}

The approval from ethical committee of the institute was obtained. This was a prospective study. All patients who underwent gynecological surgeries during August 2014 to May 2017 in the tertiary care center were included. Those were total and subtotal laparoscopic hysterectomy with or without salpingo oophorectomy wherever indicated, laparoscopy-assisted vaginal hysterectomy, total abdominal hysterectomy, and vaginal hysterectomy, repair of anterior compartment defect, transvaginal mid-urethral sling surgeries, and nonsurgical condition like chronic pelvic pain.

Relevant data were filled in study pro forma with previous history of recurrent urinary tract infection, frequency, urgency, pelvic pain related to genitourinary system. All previous medical disorders and pelvic surgeries were taken into account. Local examination of genitourinary system including per speculum and per vaginum findings were mentioned. Indication of procedure, duration, and energy sources used were mentioned. Intraoperative complications like hemorrhage, injury to adjacent structures visible intraoperatively, hematuria, and average blood loss were recorded. Single dose of Phenazopyridine (pyridium, $100 \mathrm{mg}$ ) was administered orally 4 hours prior to surgery.

At the end of the procedure, cystourethroscopy using $20 \mathrm{~F} 30^{\circ}$ rigid cystoscope was carried out under general anesthesia. The tip of the cystoscope was gently inserted into the urethra and slowly glided up into the bladder. Normal saline was used as distension media to stretch the bladder for better visualization of interior of urinary bladder. The patency, lumen, and urethrovesical junction of urethra was inspected while introducing cystoscope. After entering into the bladder, the trigone and interureteric ridge were inspected for lesion or injury, if any. The vascular pattern, active bleeding, or hyperemia was noted. Then ureteric orifices were visualized one by one on each side for their number, location, peristalsis, and jets of pyridium-stained deep-orange-colored urine through it. The jets were observed bilaterally for their presence and force as brisk or sluggish. Then whole of the lumen of bladder was inspected on right, left, anterior, posterior, and dome. The pattern of bladder mucosal lining, vascularity, injury, perforation, white patches, inflammation, ulcers, growth, calculi, mesh, intravesical or intraurethral suture, diverticula, and erythema were ruled out. In suspected cases, biopsy was taken and sent for histopathological examination.

In case suspected injury to either ureter was noted by absent or sluggish jets of deep-orange-colored urine through the orifices, retrograde pyelography was carried out for diagnosis of injury. The urethral, bladder, and ureteric injuries diagnosed intraoperatively were managed appropriately.

A study pro forma was prepared to record patient information, such as demographic data, any comorbidities, and previous surgeries with their indications in general and systemic examination including pelvic examination and cystouretheroscopic findings.

\section{RESULTS}

During the study period, total 163 subjects underwent gynecological surgeries. On 161 subjects, intraoperative cystourethroscopy was performed at the end of the procedure.

Demographic and intraoperative findings were tabulated. The majority of subjects were healthy, middle aged with normal to overweight by body mass index (BMI) as shown in Table 1.

Out of 163 patients, 91 (55.83\%) underwent total laparoscopic hysterectomy for different indications. On $10(6.13 \%)$ subjects, hysterectomy with bilateral salpingectomy, and on $8(4.8 \%)$ patients myomectomy was carried by laparotomy for better approach. Laparoscopic ovarian cystectomy was done on $6(3.68 \%)$ patients. Various types of urogynecological surgeries were performed on 48 (29.44\%) patients as described in Table 2.

The important part of our study was to detect lower urinary tract injuries with the help of routine cystourethroscopy carried intraoperatively, as mentioned in Table 3. Injury to urinary bladder was detected in $7(4.29 \%)$ patients. Out of which in $2(1.23 \%)$ patients

Table 1: Demography and clinical data of subjects involved in this study

\begin{tabular}{ll}
\hline Demographic and clinical data & Number \\
\hline Age: average & 47 \\
Range & $33-67$ \\
Parity index: nulligravida & 11 \\
$1-3$ & 113 \\
$3-5$ & 32 \\
$>5$ & 07 \\
BMI: average & 24 \\
Range & $16-35$ \\
Average operative time & 140 minutes \\
Average blood loss & $135 \mathrm{~mL}$ \\
\hline
\end{tabular}


Table 2: Type of surgery performed followed by cystourethroscopy

\begin{tabular}{ll}
\hline $\begin{array}{l}\text { Procedures performed followed } \\
\text { by cystourethroscopy }\end{array}$ & Number (\%) \\
\hline $\begin{array}{l}\text { Total laparoscopic hysterectomy + bilateral } \\
\text { salpingectomy }\end{array}$ & $91(55.83)$ \\
$\begin{array}{l}\text { Total abdominal hysterectomy + bilateral } \\
\text { salpingectomy }\end{array}$ & $10(6.13)$ \\
Vaginal hysterectomy & $11(6.74)$ \\
Transobturator tape & $16(9.81)$ \\
Transvaginal tape & $6(3.68)$ \\
Anterior mesh repair & $5(3.6)$ \\
Vaginal cyst excision & $1(0.61)$ \\
Urethrocele with perineal repair & $1(0.61)$ \\
Anterior and posterior compartment repair & $6(3.68)$ \\
Open myomectomy & $8(4.8)$ \\
Laparoscopic ovarian cystectomy with & $6(3.68)$ \\
salpingectomy & \\
Open burch colposuspension & $1(0.61)$ \\
Perigee & $1(0.61)$ \\
\hline
\end{tabular}

with history of previous lower segment cesarean section, bladder injury was detected at the time of dissecting uterovasical fold of peritoneum during total laparoscopic hysterectomy. In these subjects, bladder injury was repaired by converting procedure into laparotomy. In our study, $59(36.20 \%)$ patients had a history of laparotomy for obstetrical or gynecological indications and 2 (3.39\%) required relaparotomy for correction of bladder trauma detected by naked eyes intraoperatively only (Table 4).
Remaining 5 (3.06\%) bladder injuries were detected only after intraoperative cystourethroscopy. Those were repaired immediately. In $1(0.61 \%)$ patient, right-sided ureter was transected at the level of cervix during total laparoscopic hysterectomy. The ureteric jet of pyridiumstained urine was absent on right side during routine cystourethroscopy. The injury was confirmed by retrograde pylogram, and repaired immediately by ureteric reimplantation. In $2(1.23 \%)$ patients of total laparoscopic hysterectomy no injury was detected, in spite of bloodstained urine in urobag found before performing routine cystourethroscopy.

On long-term follow-up, it was found that 2 subjects $(1.23 \%)$ developed ureterovaginal fistula and 1 subject $(0.61 \%)$ came with leaking of urine per vaginally and diagnosed as postlaparoscopic hysterectomy vesicovaginal fistula. In all these three subjects, intraoperative cystourethroscopy findings were normal. This shows routine cystourethroscopy missed detection of lower urinary tract injury in $1.83 \%$ cases. In 1 patient $(0.61 \%)$, urinary tract infection developed in postoperative phase due to Escherichia coli (Table 5).

\section{DISCUSSION}

This is a prospective study to find out the role of universal cystourethroscopy to detect incidence and site of lower urinary tract injuries during gynecological surgeries.

Table 3: Details about site and type of low urinary tract injuries intraoperatively

\begin{tabular}{|c|c|c|c|c|c|c|}
\hline Site of injury & $\begin{array}{l}\text { Number of } \\
\text { patients (\%) }\end{array}$ & Type of injury & Procedure & $\begin{array}{l}\text { Detection on } \\
\text { cystoscopy }\end{array}$ & $\begin{array}{l}\text { Ureteric } \\
\text { peristalsis }\end{array}$ & Treatment \\
\hline \multirow[t]{5}{*}{ Bladder (4.29\%) } & $1(0.61)$ & Needle puncture & TVT & Yes & Yes & Removal of tape \\
\hline & $1(0.61)$ & Suture & TLH & Yes & Yes & Removal of suture \\
\hline & $2(1.23)$ & $\begin{array}{l}\text { Cystostomy } \\
\text { (traumatic bladder } \\
\text { opened) }\end{array}$ & $\begin{array}{l}\text { TLH (history of } \\
\text { previous } 2 \text { LSCS) }\end{array}$ & No & Not applicable & $\begin{array}{l}\text { Laparotomy followed by } \\
\text { bladder suture in two layers } \\
\text { by Vicryl } 2-0\end{array}$ \\
\hline & $1(0.61)$ & Suture & TAH & Yes & Yes & Removal of suture \\
\hline & $2(1.23)$ & $\begin{array}{l}\text { Bladder wall } \\
\text { hyperemia }\end{array}$ & TLH & Yes & Yes & $\begin{array}{l}\text { Foley's catheterization for } \\
10 \text { days }\end{array}$ \\
\hline Ureteric $(0.61 \%)$ & $1(0.61)$ & $\begin{array}{l}\text { Right ureteric } \\
\text { transection }\end{array}$ & TLH & Yes & Absent & Ureteric reimplantation \\
\hline Not detected & $2(1.23)$ & Hematuria & TLH & No & Yes & Foley's catheter for 1 week \\
\hline
\end{tabular}

TVT: Transvaginal tape; TAH: Total abdominal hysterectomy; LSCS: Lower segment cesarean section; TLH: Total laparoscopic hysterectomy

Table 4: Subjects with h/o previous pelvic surgeries

\begin{tabular}{ll}
\hline Type of surgery & $\begin{array}{l}\text { Number of } \\
\text { subjects (\%) }\end{array}$ \\
\hline None & $95(58.28)$ \\
Laparotomy (LSCS, myomectomy, etc.) & $59(36.20)$ \\
Previous laparoscopic surgery & $7(4.29)$ \\
Previous urogynec surgery & $2(1.23)$ \\
\hline LSCS: Lower segment cesarean section &
\end{tabular}

Table 5: Long-term follow-up

\begin{tabular}{ll}
\hline No morbidity indicating lower urinary tract injury & $157(\%)$ \\
Readmission for urinary tract infection & $1(0.61)$ \\
Postoperative retention of urine & $1(0.61)$ \\
Pain in right flank & $1(0.61)$ \\
Vesicovaginal fistula repair & $1(0.61)$ \\
Ureterovaginal fistula repair & $2(1.23)$ \\
\hline
\end{tabular}


Intraoperative cystoscopy can detect certain lower urinary tract injuries and helps to repair them immediately to prevent its further complications.

This study also proves that not all urinary tract injuries can be detected intraoperatively by cystourethroscopy. Urinary bladder integrity and bilateral ureteric jets of urine cannot rule out silent injuries which will manifest during postoperative period. ${ }^{11}$

In this study, we found that lower urinary tract is more vulnerable for injuries during total laparoscopic hysterectomy and transvaginal sling surgery.

Universal cystourethroscopy has shown costeffectiveness when lower urinary tract injuries exceed 1.5 to $2 \%$ during benign gynecological surgeries. ${ }^{12}$

Universal cystourethroscopy is found to be superior to detect injuries that have been missed by simple visual inspection by operating surgeon. Furthermore, immediate repair of these injuries prevents postoperative morbidities and litigations later on. There is fivefold increased detection of injuries when cystourethroscopy is performed routinely intraoperatively during gynecological surgeries. ${ }^{13}$

Those who believe selective cystourethroscopy only detects injuries to lower urinary tract and prevents procedure-related complications, such as urethral or bladder trauma and urinary tract infection postoperatively for cost-effectiveness and to cut short the overall duration of the surgery may miss the silent injuries which will increase the incidence of postoperative morbidity and potential litigations.

Diagnosis of urological injuries can be made intraoperatively or postoperatively. Mann et $\mathrm{al}^{14}$ reported that approximately $70 \%$ ureteric injuries are diagnosed postoperatively. Majority of bladder injuries are diagnosed intraoperatively. The use of intraoperative cystourethroscopy during urogynecological surgeries has shown the incidence of urological injuries as 2.6 to $8.0 \%$, ${ }^{15}$ whereas its use in major benign gynecological surgeries is found otherwise undetected injury in $0.04 \%$ cases. ${ }^{16}$

\section{CONCLUSION}

Hence, comparing cost-effectiveness and duration of procedure against postoperative morbidity due to undetected lower urinary tract injuries in selective cystourethroscopy, it is always beneficial to perform cystourethroscopy routinely at the end of every gynecological surgery.

\section{REFERENCES}

1. Mäkinen J, Johansson J, Tomás C, Tomás E, Heinonen PK, Laatikainen T, Kauko M, Heikkinen AM, Sjöberg J. Morbidity of 10110 hysterectomies by type of approach. Hum Reprod 2001 Jul;16(7):1473-1478.

2. Gilmour DT, Baskett TF. Disability and litigation from urinary tract injuries at benign gynecologic surgery in Canada. Obstet Gynecol 2005 Jan;105(1):109-114.

3. Ferro A, Byck D, Gallup D. Intraoperative and postoperative morbidity associated with cystoscopy performed in patients undergoing gynecologic surgery. Am J Obstet Gynecol 2003 Aug;189(2):354-357.

4. Schimpf MO, Gottenger EE, Wagner JR. Universal ureteral stent placement at hysterectomy to identify ureteral injury: a decision analysis. BJOG 2008 Aug;115(9):1151-1158.

5. Gilmour DT, Das S, Flowerdew G. Rates of urinary tract injury from gynecologic surgery and the role of intraoperative cystoscopy. Obstet Gynecol 2006 Jun;107(6):1366-1372.

6. Gangia MP, Agrce RE, Spence CR. Surgical injury to ureter. Urology 1976 Jul;8(1):22-27.

7. Fry DE, Milholen L, Harbrecht PJ. Iatrogenic ureteral injury: options in management. Arch Surg 1983 Apr;118(4): 454-457.

8. Harkki-Siren P, Sjoberg J, Tiitinen A. Urinary tract injuries after hysterectomy. Obstet Gynecol 1998 Jul;92(1):113-118.

9. American College of Obstetricians and Gynecologists. The role of cystourethroscopy in the generalist obstetriciangynecologist practice. ACOG Committee Opinion No. 372. Obstet Gynecol 2007 Jul;110(1):221-224.

10. AAGL Advancing Minimally Invasive Gynecology Worldwide. AAGL Practice Report: practice guidelines for intraoperative cystoscopy in laparoscopic hysterectomy. J Minim Invasive Gynecol 2012 Jul-Aug;19(4):407-411.

11. Cormio L, Ruutu M, Traficante A, Battaglia M, Selvaggi FP. Management of bilateral ureteric injuries after gynaecological and obstetric procedures. Int Urol Nephrol 1993;25(6): 551-555.

12. Visco AG, Taber KH, Weidner AC, Barber MD, Myers ER. Costeffectiveness of universal cystoscopy to identify ureteral injury at hysterectomy. Obstet Gynecol 2001 May;97(5 Pt 1):685-692.

13. Teeluckdharry B, Gilmour D, Flowerdew G. Urinary tract injury at benign gynecologic surgery and the role of cystoscopy: a systematic review and meta-analysis. Obstet Gynecol 2015 Dec;126(6):1161-1169.

14. Mann WJ, Arato M, Patsner B, Stone ML. Ureteral injuries in an obstetrics and gynecology training program: etiology and management. Obstet Gynecol 1988 Jul;72(1):82-85.

15. Tulikangas $\mathrm{PK}$, Weber $\mathrm{AM}$, Larive $\mathrm{AB}$, Walters MD. Intraoperative cystoscopy in conjunction with anti-incontinence surgery. Obstet Gynecol 2000 Jun;95(6 Pt 1):794-796.

16. Wiskind AK, Thompson JD. Should cystoscopy be performed at every gynecologic operation to diagnose unsuspected ureteral injury? J Pelvic Surg 1995 Sep;1(3):134-137. 